\title{
Dejeneratif menisküs yırtıkları
}

\author{
Degenerative meniscus lesions
}

\author{
Nurzat Elmalı, İbrahim Tuncay
}

Bezmialem Vakıf Üniversitesi Tıp Fakültesi Ortopedi ve Travmatoloji Anabilim Dalı, İstanbul

\begin{abstract}
Dejeneratif menisküs yırtığı, orta yaş ve üzerindeki kişilerde, yavaş gelişen ve genellikle horizontal klivaj yırtığı olarak görülen bir lezyondur. Akut travma öyküsü sıklıkla yoktur. En sık olarak, mediyal menisküsün gövde ve/veya arka boynuzuna yerleşir; patogenezi tam anlaşılmamıştır. Illk basamak tedavi olarak, ağrıyı azaltmak ve fonksiyonu iyileştirmek için analjezik ve fizik tedavi uygulanır. Dejeneratif menisküs yırtığında devam eden ağrı ve/veya mekanik semptomların varlığında, grafiler normal ve MR görüntülemelerinde Evre III menisküs lezyonu saptanır ise, artroskopik parsiyel menisektomi/onarımı önerilebilir. Yüklenme grafilerinde osteoartrit saptandığında, artroskopik cerrahinin yararı yoktur.
\end{abstract}

Anahtar sözcükler: dejeneratif menisküs lezyonu; osteoartrit; artroskopik parsiyel menisektomi

\begin{abstract}
A degenerative meniscus lesion is a slowly developing lesion, typically involving a horizontal cleavage of the meniscus in a middle-aged or older person. There is often no clear history of an acute knee injury. The most common location of a degenerative meniscus lesion is the body and/or posterior horn of the medial meniscus. The pathogenesis is not fully understood. First-line treatment of degenerative meniscus tears should be non-operative therapy focused on analgesia, and physical therapy to provide pain relief as well as improve function of the knee joint. Arthroscopic partial meniscectomy or repair may be proposed in the presence of persistent pain/mechanical symptoms for a degenerative meniscus with normal X-rays and abnormal MRI (Grade III meniscus lesion). Arthroscopic surgery has no benefit for a degenerative meniscus lesion with osteoarthritis diagnosed on weight bearing radiographs.
\end{abstract}

Key words: degenerative meniscus tear; osteoarthritis; arthroscopic partial meniscectomy

\section{M} enisküsler; dizde yükün aktarılması, şok emilimi, propriyosepsiyon ve eklem stabilitesi gibi önemli işlevlere sahiptir. ${ }^{[1]}$ Menisküs yırtıkları bu fonksiyonların bozulmasına ve eklem kıkırdak hasarına yol açar. ${ }^{[2-4]}$

Menisküs yırtıkları, etiyolojiye bağlı olarak travmatik veya dejeneratif olarak sınıflandırılır. Travmatik yırtıklar, sıklıkla gençlerde ve spor sırasında normal diz ve menisküse aşırı kuvvet uygulanması ile oluşan akut yırtıklardır ve semptomların başlangıcı tipik olarak travmatik olayla ilişkilidir.

Dejeneratif menisküs yırtığı ise yavaş gelişen lezyondur, travma öyküsü yoktur veya minimal travma ile meydana gelir. Patogenezi tam anlaşılmamıştır, ancak genellikle 45 yaş üzerindeki kişilerde, menisküs yapısının esnekliğinin azaldığı, dejeneratif değişikliklerin başladığı menisküs dokusunda meydana gelir. ${ }^{[2]}$

Yırtıklar, morfolojisine göre; horizontal, transvers (radyal), vertikal longitudinal ve kompleks yırtıklar olarak tanımlanır. Dejeneratif yırtıklar ise genellikle horizontal, radyal (flep tarzı) ve kompleks yırtıklardır. Esas olarak arka boynuz ve gövdede görülür (Şekil 1). ${ }^{[5]}$

\section{DEJENERATIF MENISKÜS LEZYONLARININ SIKLIĞI (EPIDEMIYOLOJi)}

Dejeneratif menisküs yırtığı; orta-ileri yaşlı, obez, temizlik ve döşeme işi gibi meslekle ilgili dizi aşırı

- İletişim adresi: Prof. Dr. Nurzat Elmalı, Bezmialem Vakıf Üniversitesi Tıp Fakültesi Ortopedi ve Travmatoloji Anabilim Dalı, Adnan Menderes Bulvarı, Vatan Cad. 34093 Fatih, İstanbul Tel: 0532 - 4359129 e-posta: nelmali@hotmail.com

- Geliș tarihi: 1 Mart $2018 \quad$ Kabul tarihi: 1 Mart 2018 

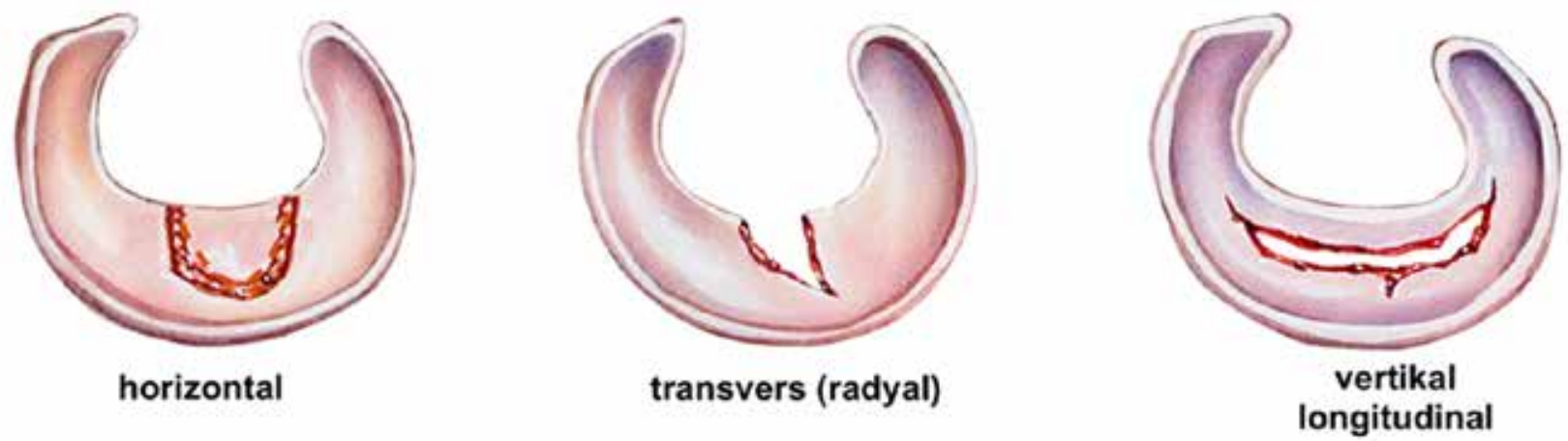

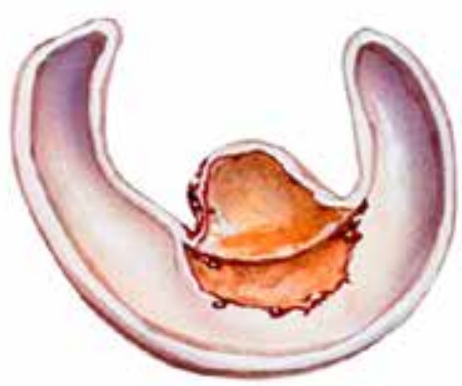

horizontal flep

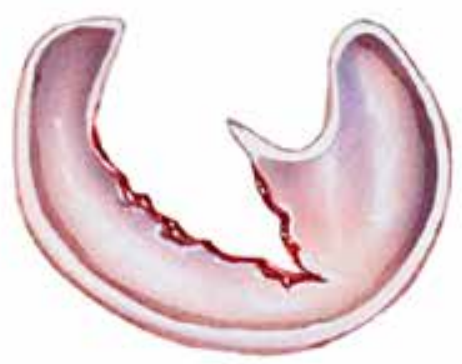

radyal flep

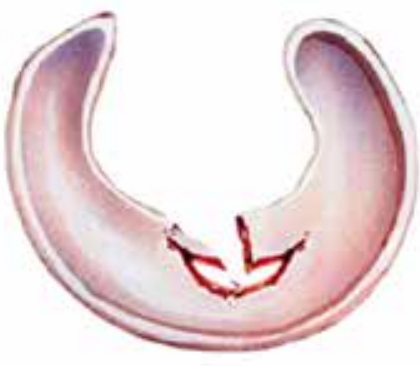

kompleks

Şekil 1. Menisküs yırtık tipleri.

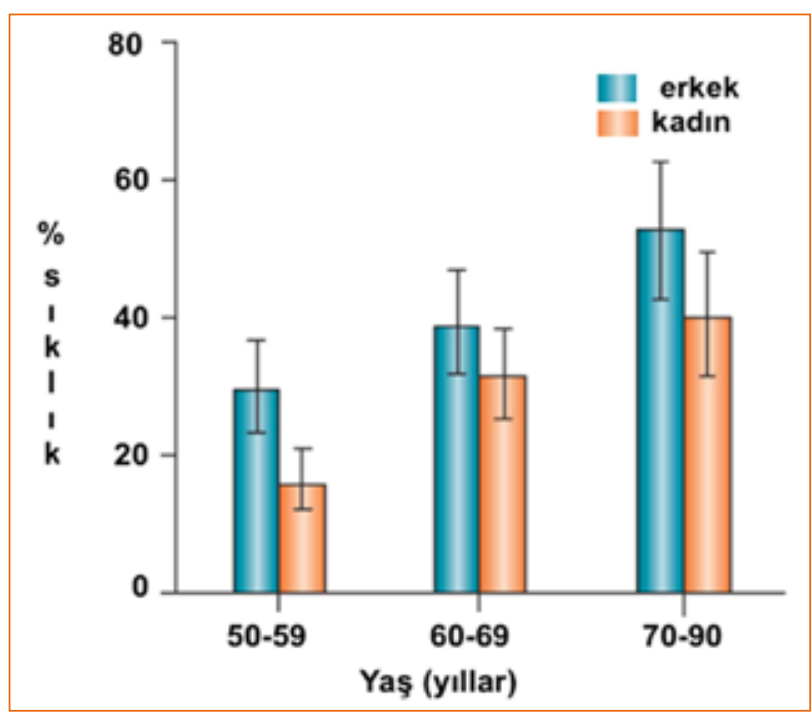

Şekil 2. Toplumda dejeneratif menisküs yırtığı sıklığı.

zorlayıcı iş yapanlarda sık görülür. Varus dizilim bozukluğu, hazırlayıcı faktör olabilir. ${ }^{[6]}$ Dizi zorlayıcı aktiviteler veya tekrarlayıcı mikrotravma, olguların \%75'inde bulunur. ${ }^{[7,8]}$ Dejeneratif menisküs yırtığı, dizde osteoartritle birlikte sık görülür. Tek taraflı diz ağrısı ile başvuran 45 yaş üzerinde 174 osteoartritli hastada yapılan bir çalışmada, semptomatik menisküs yırtığı manyetik rezonans (MR) görüntülemede \%24 bulunmuştur. ${ }^{[9]}$ Ancak, radyolojik osteoartrit bulgusu olmayan hastalarda da görülür. ${ }^{[10]}$ Mediyal menisküs, kıkırdak hasarından bağımsız olarak daha sık etkilenir.

Dejeneratif menisküs lezyonu (DML) toplumda oldukça sıktır. Yaşlanma ile birlikte sıklığı artar. DML'nin görülme sıklığı 30 yaş altındaki kişilerde \%5 iken, 30-45 yaş arasında \%13-15'e, 50-59 yaş arasında \%16-30'a ve 70 yaş üzerinde \%50'nin üzerine çıkmaktadır (Şekil 2). ${ }^{[9-14]}$ MR'de saptanan menisküs lezyonlarının semptomlara neden olması gerekmez. Framingham çalışmasında, hastaların \%60'ından fazlasında diz ağrısı şikayetinin olmadığı bildirilmiştir. ${ }^{[9]}$ Toplum temelli MR çalışmaları, diz ağrısı olmayan ve direkt grafilerinde osteoartrit bulguları olmayan orta yaş ve üzerindeki kişilerde menisküs yırtığı sıklığının yüksek olduğunu ve klinik olarak önemli olmadığını göstermiştir. ${ }^{[9-15]}$ 


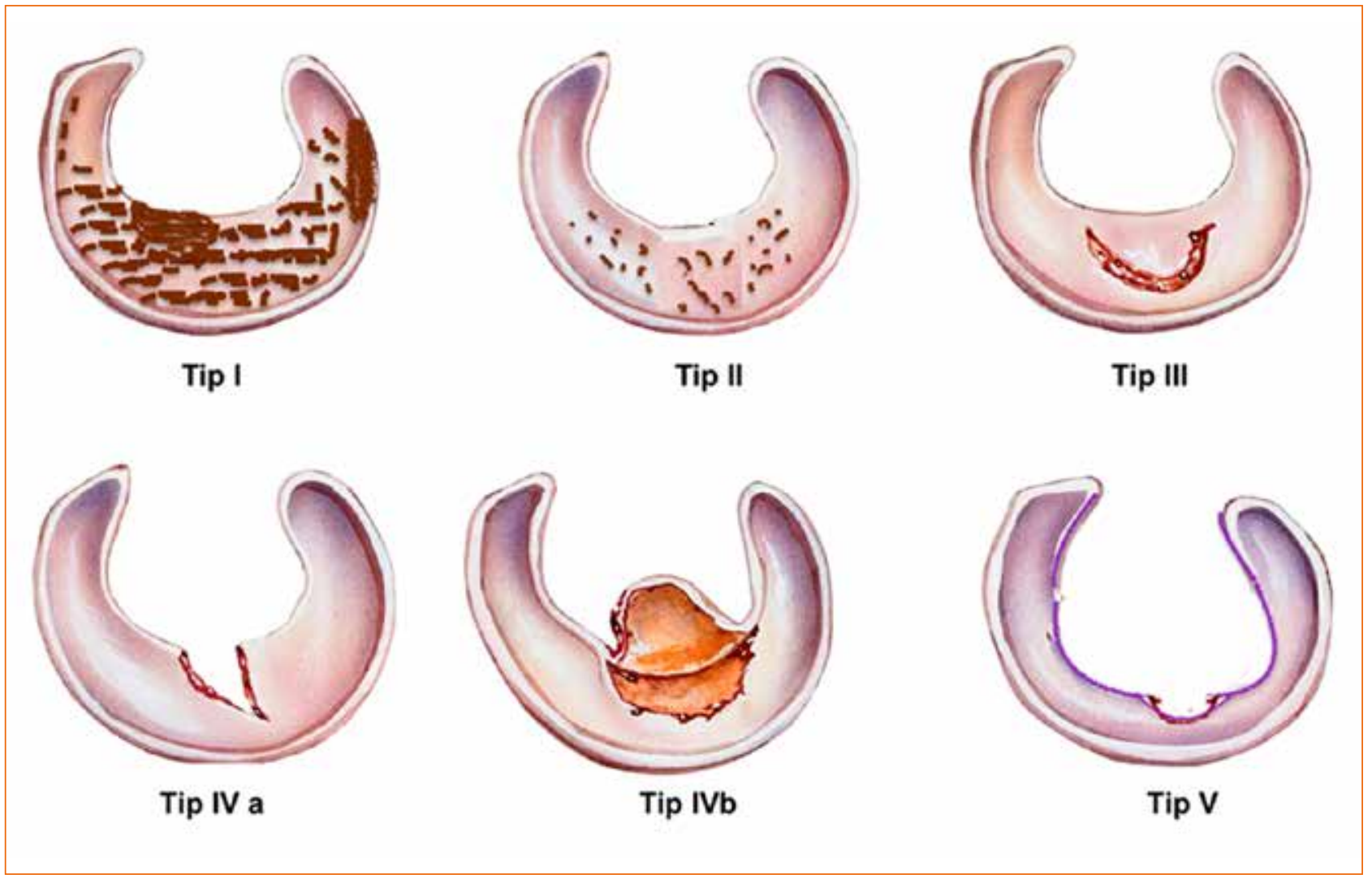

Şekil 3. Dejeneratif menisküs yırtık tipleri. Artroskopik sınıflama. ${ }^{[6]}$

\section{KLINIK SEMPTOMLAR}

Dizde ağrı, kilitlenme ve fonksiyon kaybına neden olur. Semptomlar, genellikle bilinen bir travma olmadan sinsi başlangıçlıdır. Diz ağrısı sıklıkla eklemin posteromediyal veya posterolateraline lokalizedir. Ağrı, sıklıkla geçici, bıçak saplar tarzda ciddi ve yürümekle artan niteliktedir. Dejeneratif menisküs patolojisinde, diz ağrısına takılma veya kilitlenme gibi tipik mekanik semptomlar eşlik edebilir. Ancak, 45 yaş üzerindeki kişilerde ağrının kaynağının menisküs yırtığına mı yoksa osteoartrite mi bağlı olduğunu ayırt etmek kolay değildir. Daha genç hastalarda bir yıldan daha kısa süredir devam eden lokalize diz ağrısı ile birlikte kilitlenme, takılma gibi mekanik semptomların olması menisküs yırtığında önemli iken, 45 yaşın üzerindeki hastalarda semptomatik menisküs yırtığının tanısında bu bulgular kısıtlı öneme sahiptir. Bu hastalarda varus deformitesi, eklem aralığının daralması ve diz fleksiyonunda kısıtlıIıkla birlikte yaygın diz ağrısı varsa, osteoartrit ön plandadır. ${ }^{[15]}$ Fizik muayenede, mediyal eklem hassasiyeti olguların \%70'inden fazlasında bulunur. McMurray testi hastaların sadece $1 / 3$ 'ünde pozitiftir. ${ }^{[15]}$

\section{PATOLOJi}

Yırtık olmayan menisküsün makroskopik dejeneratif lezyonları olarak; menisküs dokusu içerisinde miksoid dejenerasyonu gösteren sarı, opak sahalar, perimeniskal kistler ve menisküs kalsifikasyonları bulunur. Dejeneratif yapıda olmasına rağmen, her yaşta hastaları etkileyebilir. Mikroskopik olarak, olguların yarıdan fazlasında menisküs dokusu içinde normal mukoid substansın toplandığı miksoid dejenerasyon görülür. Hücresel elemanların tedrici kaybı ile fibröz dokuda artış bulunur. Miksoid dejenerasyon ile birlikte, bu kistik sahalar perimeniskal bölgeyi de etkileyerek yırtıklara neden olur. Eklem sıvısı yırtığı penetre eder ve eklem içi basınca bağıı menisküs duvarına doğru ilerleyerek kapsülün deformasyonuna ve perimeniskal kist oluşumuna neden olabilir. Basınç gradyentine bağlı bu sıvı eklem kavitesi içine geri boşalamaz ve kist içerisinde kalır; sonradan dehidratasyon ile jelimsi kıvama değişir. ${ }^{[16]}$ Lateral menisküsün horizontal klivaj yırtığına sekonder menisküs kistleri sık görülür (Şekil 3). ${ }^{[17]}$

DML'de menisküsün şok emici ve yükü aktarma özellikleri bozulduğundan, osteoartrit gelişme riski 
artar. Yüklenme ile, menisküsler femur ve tibia eklem yüzleri arasında deplase (extruded) olmaya eğilimlidir. Menisküsler, yapısında bulunan sirkumferensiyal kollajen lifleri sayesinde kompresif yüklenmeleri tensil yüklenmelere dönüştürür; böylece eklemdeki temas stresleri azalır ve eklem yüzeyi korunur. Bu özellik "hoop stres" mekanizması olarak bilinir. Menisküslerin periferal sirkumferensiyal dizilimli kollajen lifleri intakt olduğu sürece, hoop stres özelliği korunur ve aksiyel yükler bu kollajen lifler aracılığ ile ön arka boynuzlar arasında taşınarak, menisküsün ekstrüzyonu (radyal deplasmanı) önlenir. Parsiyel menisektomi veya kova sapı yırtıkta, periferal kenar intakt olduğu sürece menisküs fonksiyonu korunur. Buna karşılık, dejeneratif menisküste sık görülen radyal yırtık perifere uzanıyorsa, sirkumferensiyal dizilimli kollajen liflerin bütünlüğü etkilendiğinden, menisküs fonksiyonunda ciddi bozulma ve menisküsün radyal deplasmanı (extrusion) olur. Menisküs deplasmanında tibial yüzeyin örtülmesinin azalması ile hyalen kıkırdağın temas stresleri ve sonuçta tibiofemoral kıkırdak kaybı ile semptomatik osteoartrit gelişme riski artar. ${ }^{[9]}$ Christoforakis ve ark., 497 ardışık diz artroskopisinde ciddi kompleks veya horizontal klivaj yırtıklarının Outerbridge Evre III veya IV lezyonlarla birlikte olduğunu bildirmişlerdir. ${ }^{[18]}$

Osteoartrit ve dejeneratif menisküs yırtıkları, aynı risk faktörlerini ve biyolojik sürecin çoğunu paylaşır. Bu yüzden, bir durumun diğerinden önce meydana gelip gelmediğini belirlemek veya her ikisinin birbirinden bağımsız ve/veya eş zamanlı meydana geldiğini söylemek zordur. ${ }^{[19,20]}$

\section{RADYOLOJi}

Semptomatik menisküs yırtı̆̆ının tanısında altın standart yoktur. Diz ağrılı orta yaş ve üzerindeki kişilerde diz osteoartritini belirlemek için ilk kullanılacak tanısal görüntüleme, ayakta basarak çekilen anteriorposterior (AP) ve yan grafilerdir. Diz eklem semptomları olan orta yaş ve üzerindeki hastalarda ilk basamak tanı yöntemi olarak diz MR'si genellikle önerilmez. MR ancak, direkt grafilerle osteoartrit ekarte edildikten sonra osteonekroz gibi devam eden ağrının veya kilitlenme, takılma gibi tekrarlayan mekanik semptomların olması durumunda endikedir. Özellikle T2 görüntülerde lokal mukoid dejenerasyonu gösteren lineer özellikte menisküs içi sinyal değişikliğinin görülmesi, DML bulgusu olarak değerlendirilir. ${ }^{[21-23]}$

\section{MR SINIFLAMASI}

Dejeneratif menisküs yırtıklarının tanısında sıklıkla, Raunest tarafindan tanımlanan sınıflama kullanılmaktadır. ${ }^{[14]}$

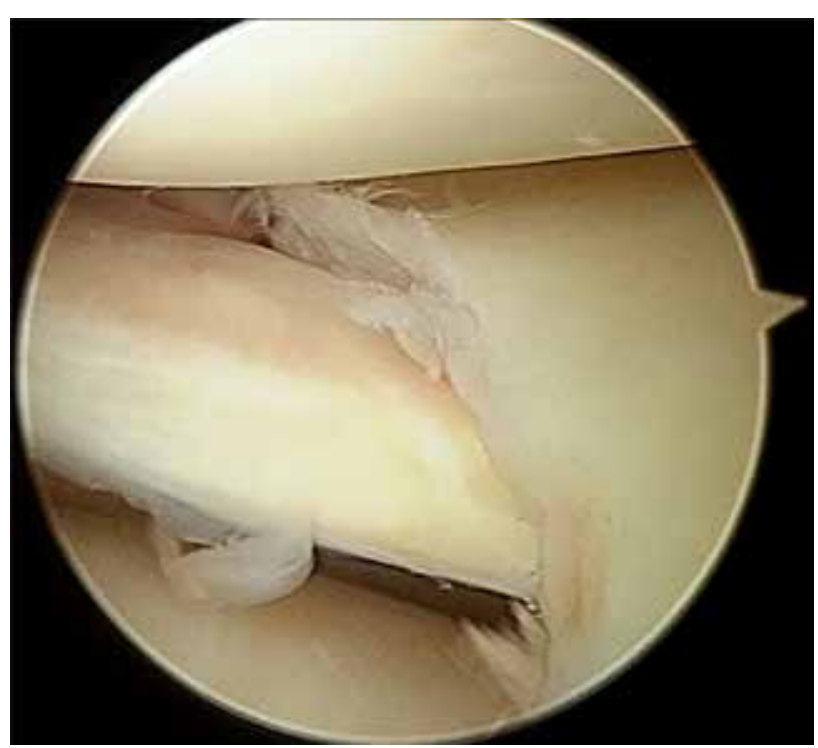

Şekil 4. Flep tarzı ayrılmış yırtı̆̆ın artroskopik görünümü.

Evre I: Eklem yüzeyine uzanmayan menisküs gövdesi içerisinde sinyal artışı.

Evre II:. Eklem yüzeyine uzanmayan menisküs gövdesi içerisinde horizontal klivaj.

Evre III: Ekleme açılan horizontal klivaj yırtığı.

\section{ARTROSKOPIK SINIFLAMA}

Dorfmann ve ark. tarafindan 2100 artroskopide saptanan 301 dejeneratif lezyona dayanılarak geliştirilen artroskopik sınıflama sıklıkla kullanılmaktadır (Şekil 4). ${ }^{[6]}$

Tip 1: Bütünlügüünde bozulma olmaksızın menisküsün yapısında değişiklik. Menisküs homojendir ama normal görünümünü kaybeder. Daha koyulaşır, yüzeyi düzensizleşir ve dalgalı görünüm alır. Bu tip, meniskozis olarak adlandırılır.

Tip II: Menisküsün gövdesi içinde ve yüzeyinde kalsiyum birikmesi ile karakterizedir (meniskokalsinozis).

Tip III: Horizontal klivaj yırtığı.

Tip IV: Radyal yırtık, mediyal menisküsün iç kenarından köken alır, menisküs gövdesi ile arka boynuz kavşağında oblik seyirlidir. Bazen perifere kadar uzanır (IVa); probla palpe edildiğinde hareketli ve flep tarzında ayrilıyorsa Tip IVb olarak adlandırılır.

Tip V: Tanımlanamayan kompleks lezyonun varlığı. Nadirdir, ancak osteoartritik dizlerde görülür. 
Artroskopi altın standarttır, fakat menisküs yüzeyine uzanmayan lezyonları belirleyemez. MR ve artroskopi uyumu pek çok çalışmada değerlendirilmiştir. ${ }^{[26-29]}$ Fischer ve ark.'na göre, mediyal menisküs için duyarlılık ve spesifisite $\% 89$ ve $\% 84$, lateral menisküs için $\% 69$ ve $\% 94$ bulunmuştur. ${ }^{[24]}$

\section{TEDAVi}

Diz ağrısı ile birlikte olan dejeneratif menisküs yırtığında konservatif tedavi, her zaman ilk seçilecek tedavi olmalıdır. Amaç, akut semptomları gidermek ve gelecekte nüksü önlemektir. Konservatif tedavide, semptomları ortaya çıkaran aktivitelerin kısıtlanması ve gerekirse non-steroid anti-inflamatuvar (NSAI) ilaçlar kullanılabilir. Fizik tedavide, eklem hareket açıklığını (ROM) koruyucu, kalça ve hamstring fleksibilitesini iyileştirici ve diz propriyosepsiyonunu koruyucu egzersizler uygulanır.

Beraberinde osteoartrit olmadan veya hafif osteoartriti bulunan orta yaşlı hastalardaki dejeneratif menisküs yırtıklarının tedavisinde, artroskopik parsiyel menisektomi (APM) sıklıkla yapılmaktadır. Ancak, sık yapılmasına rağmen son yıllarda APM'nin yararı tartışılmaktadır. Menisektomiden sonra uzun dönem takip çalışmalarında, 21 yıldan sonra osteoartritin radyolojik bulgularının gelişmesinin 14 kat daha fazla olduğu bildirilmiştir. ${ }^{[25]}$ Kyrish ve ark.'nın yaptığı çalışmada, semptomatik dejeneratif mediyal menisküs posterior kök yırtıklarının tedavisinde parsiyel menisektominin artritik sürecin ilerlemesini durdurmada yararının olmadığı, bu hastaların beş yıllık izlemlerinde artritik sürecin devam ettiği ve hastaların \%54'üne artroplasti yapıldığı bildirilmiştir. ${ }^{[26]}$

En az üç ay konservatif tedaviye rağmen ağrı ve kilitlenme gibi mekanik semptomları devam eden, direkt grafileri normal veya minimal osteoartritik değişikliği olan ve MR'de Evre III menisküs lezyonu olan hastalar için, APM veya menisküs onarımı önerilebilir. Çeşitli çalışmalarda, DML için konservatif tedavi uygulanan hastaların \%7-30'una daha sonra artroskopik girişim yapıldığı bildirilmiştir. ${ }^{[27,28]}$ Uygun tedavinin seçimi belli kriterlere göre yapılır. Horizontal bir yırtıkta çevresel kollajen liflerinin menisküsteki sürekliliği halen korunacağı için, yırtık doku iyi bir işleve sahip olabilir. Menisküsün geniş eksizyonu fonksiyonel dokunun kaybolmasına ve dolayısıyla gelecekte artrite neden olabilir. Bu nedenle, menisküsün onarılması veya girişim yapılmadan bırakılması daha uygundur. Buna karşılık, radyal veya düzensiz kompleks yırtıklarda, menisküs dokusu yaralanma anında fonksiyonunu kaybetmiştir. Böyle bir durumda yapılan APM'nin amacı, özellikle yırtık belirtilerini hafifletmektir.
Bazen MR'de, lateral menisküs horizontal yırtığı ile birlikte menisküs kisti bulunur. Ağrılı kistlerin tedavisinde, başlangıçta eklem veya kist içerisine steroid enjeksiyonu yapılır. Bu tedaviler yeterli olmazsa, menisküs onarımı ile birlikte kistin drenajı yapılır. ${ }^{[29,30]}$ Birkaç meta-analiz ve sistematik derleme çalışmada, beraberinde osteoartrit olmadan veya hafif osteoartriti bulunan orta-yaşlı hastalardaki dejeneratif menisküs yırtıklarının tedavisinde, artroskopik parsiyel menisektominin plasebo (sham) tedaviye veya cerrahi dışı tedaviye üstünlüğünün olmadığı gösterilmiştir. [31-34] Sihvonen ve ark., 35-65 yaş arası bir grup hastada APM ile plasebo cerrahiyi karşılaştırmışlardır. Çok merkezli FIDELITY çalışmasında, 900'den fazla hastanın ileriye dönük randomize değerlendirilmesinde, dejeneratif menisküs yırtığı ve diz ağrısı olan hastaların artroskopik cerrahiden tatmin oranının düşük olduğu ve artroskopik cerrahinin plasebo cerrahiden daha iyi olmadığı bildirilmiştir. ${ }^{[31]}$ Aynı çalışmanın devamında, 146 hastanın iki yıllık izleminde, kilitlenme gibi mekanik semptomları olan veya başlangıç konservatif tedavinin yetersiz olduğu hastalarda, parsiyel menisektominin plasebo cerrahiden daha iyi olduğu gösterilememiştir. ${ }^{[32]}$

Dejeneratif menisküs yırtığı bulunan ciddi diz osteoartritli (Kellgren-Lawrence Evre III-IV) orta yaşlı hastalarda artroskopik parsiyel menisektominin yararı gösterilmemiştir. Moseley ve ark. tarafından 2002 yılında NEJM'de yayımlanan çalışma, oyun değiştirici olarak yerini almıştır. Bu araştırmacılar, diz osteoartritli 180 hastaya randomize olarak artroskopik debridman, artroskopik lavaj ve plasebo cerrahisi (sadece cilt insizyonu) uygulamışlardır. İki yıllık izlemde, her üç grup da ağrıda azalma bakımından benzer iyileşme göstermiştir. Sonuç olarak, yazarlar artroskopik cerrahinin plasebo cerrahiye ek bir yarar sağlamadığını bildirmişlerdir. ${ }^{[33]}$ Sonraki çalışmalarda, cerrahi yapılmayan hasta grubunun olmayışı ve sonuçların yanlış yorumlandığı gibi eleştiriler yapılsa da, bu çalışmanın yayımlanmasından sonra diz osteoartritli hastalarda artroskopik girişim sayısı oldukça azalmıştır. Kirkley ve ark., radyografik olarak diz osteoartriti bulunan (iki ya da fazla kompartmanda Kellgren-Lawrence Evre IV osteoartrit bulguları olan) hastalarda standardize fizik tedavi programına karşılık, artroskopik debridman ve fizik tedavi yapılan hastaları karşılaştırmışlardır. Artroskopik debridman ve fizik tedavi yapılan grupta ilk üç ayda semptomların iyileşmesi sadece fizik tedavi yapılan gruptan daha iyi bulunmuş, ancak sonraki izlemlerde ağrı ve fonksiyonda iyileşme bakımından her iki grup arasında farklılık bulunmamıştır. ${ }^{[34]}$

Artroskopinin yarar ve zararlarını değerlendiren bir sistematik derleme ve meta-analiz çalışmasında, 
osteoartriti olan veya olmayan, orta yaşlı veya yaşlı hastalarda, çok sınırlı endikasyonlar dışında artroskopik cerrahinin yararının olmadığı, aksine zarar verdiği bildirilmiştir. ${ }^{[35]}$ İsviçre sağlık kayıtlarında, dejeneratif menisküs yırtığı için bir yılda yapılan 4000 artroskopik girişimin maliyetinin 4 milyon Euro olduğu bildirilmiştir. Bu, etkinliği şüpheli olan bir cerrahi hiçbir zaman ekonomik olarak etkin kabul edilmez. ${ }^{[36]}$

Sonuç olarak; kilitli diz veya tekrarlayan kilitlenmeler gibi mekanik semptomlar ve genç hastalar dışarıda tutulduğunda, ameliyat öncesi semptomlara bakılmaksızın, osteoartritle birlikte olsun veya olmasın, orta yaşlı ve yaşlı hastalardaki dejeneratif menisküs lezyonu için artroskopik cerrahiye karar verirken aşırı dikkatli olmak gerekir ve ilk basamak tedavi olarak cerrahi önerilmemelidir. Illk önce konservatif tedavi seçilmelidir. Üç aylık konservatif tedaviden sonra belirgin mekanik semptomları olan, normal X-ray'ler ve MR'de Evre III menisküs lezyonu olan hastalarda artroskopik girişim önerilebilir. Yüklenme grafilerinde osteoartriti olan dejeneratif menisküs lezyonlarında, artroskopik cerrahinin yararı yoktur.

\section{KAYNAKLAR}

1. Fox AJS, Bedi A, Rodeo SA. The Basic Science of Human Knee Menisci Sports Health. Sports Health 2012;4(4):340-51. Crossref

2. Noble J, Hamblen DL. The pathology of the degenerate meniscus lesion. J Bone Joint Surg Br 1975;57-B(2):180-6. Crossref

3. Englund M, Roos EM, Lohmander LS. Impact of type of meniscal tear on radiographic and symptomatic knee osteoarthritis: a sixteen-year followup of meniscectomy with matched controls. Arthritis Rheum 2003;48(8):2178-87. Crossref

4. Bhattacharyya T, Gale D, Dewire P, Totterman S, Gale ME, McLaughlin S, Einhorn TA, Felson DT. The clinical importance of meniscal tears demonstrated by magnetic resonance imaging in osteoarthritis of the knee. J Bone Joint Surg Am 2003;85(1):4-9. Crossref

5. Poehling GG, Ruch DS, Chabon SJ. The landscape of meniscal injuries. Clin Sports Med 1990;9(3):539-49.

6. Dorfmann H, Juan LH, Bonvarlet JP, Boyer T. Arthroscopy of degenerative lesions of the internal meniscus. Classification and treatment. Rev Rhum Mal Osteoartic 1987;54(4):303-10.

7. Englund M, Felson DT, Guermazi A, Roemer FW, Wang K, Crema MD, Lynch JA, Sharma L, Segal NA, Lewis CE, Nevitt MC. Risk factors for medial meniscal pathology on knee MRI in older US adults: a multicentre prospective cohort study. Ann Rheum Dis 2011;70(10):1733-9. Crossref

8. Pauli C, Grogan SP, Patil S, Otsuki S, Hasegawa A, Koziol J, Lotz MK, D'Lima DD. Macroscopic and histopathologic analysis of human knee menisci in aging and osteoarthritis. Osteoarthritis Cartilage 2011;19(9):1132-41. Crossref

9. Englund $M$, Guermazi $A$, Gale D, Hunter DJ, Aliabadi $P$, Clancy M, Felson DT. Incidental meniscal findings on knee MRI in middle- aged and elderly persons. $N$ Engl J Med 2008;359(11):1108-15. Crossref
10. Berthiaume MJ, Raynauld JP, Martel-Pelletier J, Labonte F, Beaudoin G, Bloch DA, Choquette D, Haraoui B, Altman RD, Hochberg M, Meyer JM, Cline GA, Pelletier JP. Meniscal tear and extrusion are strongly associated with progression of symptomatic knee osteoarthritis as assessed by quantitative magnetic resonance imaging. Ann Rheum Dis 2005;64(4):556-63. Crossref

11. Fahmy NR, Williams EA, Noble J. Meniscal pathology and osteoarthritis of the knee. J Bone Joint Surg Br 1983;65$B(1): 24-8$. Crossref

12. Beattie KA, Boulos $P$, Pui $M$, O'Neill J, Inglis $D$, Webber CE, Adachi JD. Abnormalities identified in the knees of asymptomatic volunteers using peripheral magnetic resonance imaging. Osteoarthritis Cartilage 2005;13(3):1816. Crossref

13. Guten GN, Kohn HS, Zoltan DJ. 'False positive' MRI of the knee: a literature review study. WMJ 2002;101(1):35-8.

14. Raunest J, Hötzinger $H$, Bürrig KF. Magnetic resonance imaging (MRI) and arthroscopy in the detection of meniscal degenerations: correlation of arthroscopy and MRI with histology findings. Arthroscopy 1994;10(6):634-40. Crossref

15. Jerosch J, Castro WH, Assheuer J. Age-related magnetic resonance imaging morphology of the menisci in asymptomatic individuals. Arch Orthop Trauma Surg 1996;115(3-4):199-202. Crossref

16. Höpker WW, Angres G, Klingel K, Komitowksi D, Schuchardt E. Changes of the elastin compartment in the human meniscus. Virchows Arch A Pathol Anat Histopathol 1986;408(6):575-92. Crossref

17. Ferrer-Roca $O$, Vilalta $C$. Lesions of the meniscus. Part 1: macroscopic and histologic findings. Clin Orthop Relat Res 1978;(146):289-300. Crossref

18. Christoforakis J, Pradhan R, Sanchez-Ballester J, Hunt N, Strachan RK. Is there an association between articular cartilage changes and degenerative meniscus sears? Arthroscopy 2005;21(11):1366-9. Crossref

19. Hunter DJ, Zhang YQ, Niu JB, Tu X, Amin S, Clancy M, Guermazi A, Grigorian M, Gale D, Felson DT. The association of meniscal pathologic changes with cartilage loss in symptomatic knee osteoarthritis. Arthritis Rheum 2006;54(3):795-801. Crossref

20. Guermazi A, Niu J, Hayashi D, Roemer FW, Englund M, Neogi T, Aliabadi P, McLennan CE, Felson DT. Prevalence of abnormalities in knees detected by MRI in adults without knee osteoarthritis: population based observational study (Framingham Osteoarthritis Study). BMJ 2012;345(1):e5339. Crossref

21. Kumm J, Roemer FW, Guermazi A, Turkiewicz A, Englund M. Natural History of Intrameniscal Signal Intensity on Knee MR Images: Six Years of Data from the Osteoarthritis Initiative. Radiology 2016;278(1):164-71. Crossref

22. LaPrade RF, Burnett QM 2nd, Veenstra MA, Hodgman CG. The prevalence of abnormal magnetic resonance imaging findings in asymptomatic knees. With correlation of magnetic resonance imaging to arthroscopic findings in symptomatic knees. Am J Sports Med 1994;22(6):739-45. Crossref

23. Hodler J, Haghighi P, Pathria MN, Trudell D, Resnick D. Meniscal changes in the elderly: correlation of MR imaging and histologic findings. Radiology 1992;184(1):221-5. Crossref

24. Fischer SP, Fox JM, Del Pizzo W, Friedman MJ, Snyder SJ, Ferkel RD. Accuracy of diagnoses from magnetic resonance imaging of the knee. A multi-center analysis of one thousand and fourteen patients. J Bone Joint Surg Am 1991;73:2-10. Crossref 
25. McDermott ID, Amis AA. The consequences of meniscectomy - review. J Bone Joint Surg Br 2006;88-B(12):1549-56. Crossref

26. Krych AJ, Johnson NR, Mohan R, Dahm DL, Levy BA, Stuart MJ. Partial meniscectomy provides no benefit for symptomatic degenerative medial meniscus posterior root tears. Knee Surg Sports Traumatol Arthrosc 2018;26(4):1117-22. Crossref

27. Yim JH, Seon JK, Song EK, Choi JI, Kim MC, Lee KB, Seo HY. A comparative study of meniscectomy and nonoperative treatment for degenerative horizontal tears of the medial meniscus. Am J Sports Med 2013;41(7):1565-70. Crossref

28. Herrlin SV, Wange PO, Lapidus G, Hållander M, Werner S, Weidenhielm L. Is arthroscopic surgery beneficial in treating non-traumatic, degenerative medial meniscal tears? A five year follow-up. Knee Surg Sports Traumatol Arthrosc 2013;21(2):358-64. Crossref

29. Lu KH. Arthroscopic meniscal repair and needle aspiration for meniscal tear with meniscal cyst. Arthroscopy 2006;22(12):1367.e1-e4. Crossref

30. Beaufills P, Hardy P, Chambat P, Clavert P, Djian P, Frank A, Hulet C, Potel JF, Verdonk R; Société Française d'Arthroscopie. Adult lateral meniscus. Rev Chir Orthop Reparatrice Appar Mot 2006;92(5 Suppl):2S169-94.

31. Sihvonen R, Paavola M, Malmivaara A, Järvinen TL. Finnish Degenerative Meniscal Lesion Study (FIDELITY): a protocol for a randomised, placebo surgery controlled trial on the efficacy of arthroscopic partial meniscectomy for patients with degenerative meniscus injury with a novel 'RCT withina-cohort' study design. BMJ Open 2013;9;3(3):e002510. Crossref
32. Sihvonen R, Paavola M, Malmivaara A, Itälä $A$, Joukainen $A$, Nurmi $H$, Kalske J, Ikonen $A$, Järvelä $T$, Järvinen $T A H$, Kanto $\mathrm{K}$, Karhunen J, Knifsund J, Kröger $\mathrm{H}$, Kääriäinen $\mathrm{T}$, Lehtinen J, Nyrhinen J, Paloneva J, Päiväniemi O, Raivio M, Sahlman J, Sarvilinna R, Tukiainen S, Välimäk Wi, Äärimaa V, Toivonen $\mathrm{P}$, Järvinen TLN. Arthroscopic partial meniscectomy versus placebo surgery for a degenerative meniscus tear: a 2-year follow-up of the randomised controlled trial. Extended report. Ann Rheum Dis 2017;77(2):188-95. Crossref

33. Moseley JB, O'Malley K, Petersen NJ, Menke TJ, Brody BA, Kuykendall DH, Hollingsworth JC, Ashton CM, Wray NP. A controlled trial of arthroscopic surgery for osteoarthritis of the knee. N Engl J Med 2002;347(2):81-8. Crossref

34. Kirkley A, Birmingham TB, Litchfield RB, Giffin JR, Willits KR, Wong CJ, Feagan BG, Donner A, Griffin SH, D'Ascanio LM, Pope JE, Fowler PJ. A randomized trial of arthroscopic surgery for osteoarthritis of the knee. $N$ Engl J Med 2008;359(11):1097-107. Crossref

35. Thorlund JB, Juhl CB, Roos EM, Lohmander LS. Arthroscopic surgery for degenerative knee: Systematic review and metaanalysis of benefits and harms. BMJ 2015;350(3):h2747. Crossref

36. Marsh JD, Birmingham TB, Giffin JR, Isaranuwatchai W, Hoch JS, Feagan BG, Litchfield R, Willits K, Fowler P. Costeffectiveness analysis of arthroscopic surgery compared with non-operative management for osteoarthritis of the knee. BMJ Open 2016;6(1):e009949. Crossref 